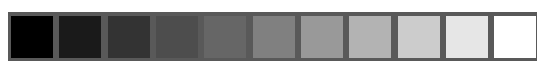

\title{
Cultura e civilização na Amazônia: Rondon e o projeto civilizador do Estado brasileiro (1927-1930)
}

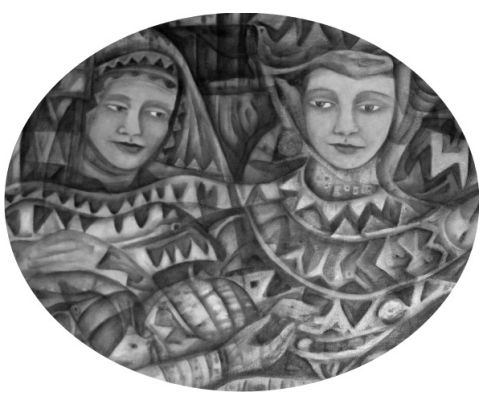

Fernando da Silva Rodrigues*

\section{Resumo}

Este estudo procura analisar as imagens fotográficas produzidas sobre negros e índios da Amazônia pela Comissão de Inspeção de Fronteiras, durante os anos de 1927 a 1930, chefiada pelo General Cândido Mariano da Silva Rondon, articulando essa produção documental com os interesses modernizadores do Estado brasileiro naquele momento em que o país continuava na busca pela sua identidade.

Palavras-chave: Cultura. Civilização. Estado.

\section{Abstract}

This study tries to analyze the photographic images produced on Blacks and Indians of Amazonia by the Border Inspection Committee, from 1927 to 1930, under the command of General Cândido Mariano da Silva Rondon, by articulating this documentary production with the modernizing interests of the Brazilian State at that moment where the country continued in the quest for its identity.

Keywords: Culture. Civilization. State.

\footnotetext{
Doutor em História Política pela Universidade do Estado do Rio de Janeiro. Atualmente é Professor da Graduação de História da UNIABEU e pesquisador do acervo institucional e iconográfico do Arquivo Histórico do Exército. Tem experiência na área de História, com ênfase em História Política e Militar, atuando principalmente nos seguintes temas: política, Estado, memória, militares, iconografia e cultura. 
Este artigo tem por objetivo analisar o projeto civilizador do Estado brasileiro para os grupos indígenas do sertão da Amazônia. Ação personificada, principalmente, na figura do General de Divisão Cândido Mariano da Silva Rondon, engenheiro e militar, que desempenhou algumas de suas funções no Exército brasileiro de maneira a cumprir determinações do Estado, primeiro, de integrar o litoral ao interior, através da construção de linhas telegráficas, símbolo do progresso e da modernidade; e, segundo, pela demarcação das fronteiras terrestres como fechamento de um ciclo em que o Brasil vinha de longa data tentando estabelecer o domínio sobre o território que antes pertencia à Espanha e que foi incorporado ao espaço geográfico português, e, posteriormente, passa a pertencer ao Estado brasileiro com sua independência política.

Tratarei especificamente neste artigo da análise das imagens fotográficas produzidas pela Comissão de Inspeção de Fronteiras, entre os anos de 1927 e 1930, chefiada pelo General Rondon, articulada à ideia de intervenção do Estado através do processo civilizador, e como fonte documental que compõe essa intervenção sobre o espaço e grupos sociais que precisam ser dominados.

As fotografias analisadas integram cinco álbuns da Comissão de Inspeção de Fronteiras que se encontram no Arquivo Histórico do Exército. Os álbuns estão assim divididos: primeiro, Pará e Amazonas, no ano de 1927; segundo, refere-se à Campanha de 1928/1929 (Primeira Parte), da cidade de Óbidos, rio Amazonas, ao alto da Cachoeira Grande; terceiro, a Campanha de 1928/1929 (Segunda Parte), da Barra do rio Marapi sobre o rio Paru do Cuminá ao acampamento da Cabeceira Rica ao sopé do Pico Ricardo Franco e Campos Gerais ao Sul da Serra de Tumucumaque, no Estado do Pará; quarto, a Campanha de 1927/1928 (Terceira Parte), que são panoramas fotográficos do topo do Pico Ricardo Franco para documentar a conformidade do Arco formado pela Serra Tumucumaque, na cabeceira do rio Paru do Cuminá, com a presença de índios Tiriós, Rangus e Uianás; e, por último, o quinto álbum da Campanha de 1929/1930 (Segunda Parte), da Barra do rio Acre sobre o rio Purus no Estado do Amazonas, à mina de manganês de Urucum, na cidade de Corumbá, no Mato Grosso.

No material documental produzido pelas turmas de inspeção de fronteiras percebi uma grande parcela deles privilegiando o tema espaço geográfico e que confirmariam uma intenção de se estudar o meio natural do sertão brasileiro o qual 
seria utilizado não só para reconhecimento das nossas fronteiras terrestres como também para estudos geopolíticos visando a futuras intervenções diretas do Estado.

O estudo das culturas encontradas tornou-se um complemento da avaliação territorial, visto que uma intervenção do Estado fatalmente passaria por todos os campos, desde o material até o pessoal. Percebi, nos álbuns analisados, uma grande quantidade de imagens produzidas dos grupos indígenas brasileiros e de países fronteiriços, além do registro de algumas imagens de negros que habitavam as regiões percorridas pela expedição. Estes estudos etnográficos tinham por objetivo estabelecer o grau de desenvolvimento material destes grupos considerados inferiores, e facilitar o processo civilizatório e intervencionista.

O período de 1927 a 1930 foi crucial para a História Política do Brasil, com relação ao estabelecimento das fronteiras Norte e Centro-Oeste. O telégrafo de Rondon tomou posse sobre o Centro-Oeste e a Amazônia, mas a Comissão de Inspeção de Fronteiras completara o trabalho de consolidação de nossa soberania territorial, ratificando as nossas reais fronteiras.

Em 1927, o então presidente Washington Luiz determina que sejam inspecionadas as fronteiras do país até o final de seu governo, com o objetivo de estudar as condições de seu povoamento e segurança, sendo então o General Rondon nomeado Inspetor de Fronteira. A inspeção no Norte e no Centro-Oeste tinha por objetivo atingir a linha de fronteiras do Brasil com a Guiana Francesa, Guiana Holandesa, Guiana Inglesa, Venezuela, Colômbia, Peru, e Bolívia, divididas em campanhas.

A primeira campanha iniciou-se pelo norte do país, abrangendo as fronteiras dos Estados do Pará e Amazonas, com a Guiana Francesa, Guiana Inglesa e o Sul da Venezuela. A segunda campanha partiu do Estado do Pará com destino à fronteira com a Guiana Holandesa. E a terceira campanha visou o interior do país, seguindo do Amazonas ao Estado do Mato Grosso.

Em minha pesquisa sobre o período inicial do século XX, constatei que foi marcado por um intenso processo civilizador promovido pelo Estado brasileiro, tendo como embasamento o contexto internacional. Ou seja, onde fosse necessário, o "homem civilizado" continuava pronto para levar a civilização aos "bárbaros e selvagens", através de uma catequização contemporânea cujo principal instrumento era o sistema educacional. 
No entanto, para discutir o conceito de civilização e barbárie desta pesquisa, tomei como base teórica as análises clássicas do sociólogo Norberto Elias, na obra, O Processo Civilizador: uma história dos costumes, considerado por muitos historiadores como uma das mais importantes obras contemporânea. Para Elias, o conceito de civilização pode se referir ao nível tecnológico, às ideias e aos costumes de uma sociedade. Também pode tratar das habitações, das relações entre homens e mulheres, das punições do sistema jurídico ou da preparação dos alimentos.

Este conceito de civilização tem como base o pensamento europeu ocidental, apesar desse conceito não ter o mesmo significado em todas as nações do Ocidente, diferenciando-se a forma inglesa e francesa da forma alemã.

$\mathrm{Na}$ forma inglesa e francesa, o termo civilização pode se referir a questões políticas, econômicas, religiosas, sociais ou morais. $\mathrm{Na}$ forma alemã, tem como base os fatores intelectuais, artísticos e também religiosos. Para Norbert Elias, civilização faz parte de um processo em desenvolvimento.

O conceito de civilização teve a função de contrapor, dentro de uma sociedade, a imagem da elite européia da de outros membros considerados mais simples ou inferiores, pelo tipo específico de comportamento que transforma o outro em diferente, em bárbaro e que se traduz dentro das novas unidades políticas da Europa, na nova formação social, a da sociedade de corte.

É um conceito criado dentro de uma teoria evolucionista européia, partindo de uma visão etnocêntrica e que se desenvolveu ao longo do século XIX, no qual o discurso historiográfico ganhava foros científicos, e o historiador tornava-se um de seus pesquisadores. O contexto político é o da consolidação do Estado Nacional, que deve manter a ordem e o status quo.

Com Carlos Linneo, naturalista do século XVIII, temos a consolidação da identidade dos grupos humanos, tomando como base os aspectos físicos e biológicos junto a traços comportamentais morais predominantes, e que acabou definindo as raças: o asiático, cruel e melancólico; o africano, malevolente e astuto; e o branco, genial e inventivo. Já em Gobineau percebe-se um continuísmo dessa teoria ao desenvolver seus estudos sobre as raças e suas desigualdades, sendo que a inovação vem com a denúncia de que o processo de miscigenação trazia a decadência das particularidades inerentes a cada raça.

Como verificamos, a biologia, como critério teórico legitimador e excludente, se impôs dentro do processo de desenvolvimento das ciências naturais durante os

62 Somanlu, ano 8, n. 2, jul./dez. 2008 
séculos XVIII e XIX. Foram os elementos científicos que preservaram a superioridade ocidental, agora nas categorias laicas e racionais, em substituição às categorias religiosas, tudo dentro da manutenção do discurso do outro, do diferente, que mantém a estabilidade da ordem desejada. O século XIX é o momento em que a Europa ocidental promove novo processo expansionista colonial ao mundo bárbaro, mantida sob a proteção de um projeto missionário que leva ao outro o processo civilizador. O darwinismo científico que inspira o pensamento antropológico do século XIX legitima esse novo colonialismo que, assim, não se caracteriza apenas como produto de certa conjuntura política, mas também de uma estrutura biológica, ou seja: a Antropologia do século XIX justifica a Europa imperialista.

A segunda metade do século XIX e o início do XX referem-se ao momento de aprimoramento do conceito de raça, dentro de uma perspectiva científica biológica, que foi aplicada aos modelos políticos europeus de colonização. Buscavam nas diferenças físicas entre os homens indícios de caráter e personalidade. O objetivo era legitimar os domínios, a tutela, o extermínio contra o atraso histórico das culturas não-ocidentais.

O discurso etnológico ${ }^{1}$ foi usado de maneira discriminatória e com conclusões implicitamente políticas. Seu principal pressuposto era, muitas vezes, a evolução linear, em que, à frente da humanidade, estava a Europa, pioneira da civilização e, atrás, os povos primitivos da África, Oceania e Amazônia. O outro, o atrasado, o bárbaro, o selvagem é sempre diferente, hierarquizado pela sua diferença. A etnologia recebeu a missão de estudar essas culturas diferentes dentro do contexto dos interesses políticos europeus. Analista dessas sociedades inferiores, do folclore, a visão etnológica era muitas vezes tendenciosa e, na melhor das hipóteses, paternalista.

O Estado brasileiro, no final do século XIX, tinha como proposta política construir uma nação soberana e civilizada. A busca da cidadania não se concretizara, dificultando a formação de uma nação no sentido republicano, ou seja, uma nação onde seus cidadãos fossem livres e iguais, que tivessem um sentimento coletivo de identidade e com certo nível de participação. Logo, entendemos que uma das fases da construção da nacionalidade passou pela intervenção do Estado no processo civilizador, de forma a garantir a soberania sobre o território. Havia a necessidade de se ter um povo brasileiro, o qual seria a base para a formação da nação, mas, no

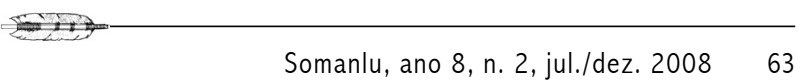


final do século XIX, eram suficientes para manter o Estado os homens livres, que tinham alguma posse, com algumas características culturais e biológicas de homem civilizado, se possível alfabetizado e de pele clara.

A forte miscigenação da população brasileira era considerada pela elite um obstáculo ao processo civilizador, ou mesmo uma vergonha frente às nações européias, pois, de acordo com as teorias evolucionistas do século XIX, a ideia de civilização está vinculada à raça branca ou, pelo menos, à sua hegemonia sobre outras raças. A questão racial no Brasil criou diversos problemas com relação à nação que se queria. Um questionamento está relacionado à condição de negros e índios tornarem-se cidadãos ou, então, como lidar com uma população de nãobrasileiros que habitam as terras brasileiras? A solução de parte do problema da nação foi obtida pela emancipação dos negros e pela civilização dos grupos indígenas, estabelecendo, assim, certa homogeneidade social e cultural que ampliou as bases demográficas do Brasil.

No Brasil republicano houve a necessidade de dar continuidade à política estratégica do Império de controle das populações indígenas localizadas nas fronteiras, com o intuito de garantir a soberania territorial conquistada a partir da segunda metade do século XVIII. Era preciso lançar mão dos conhecimentos arqueológicos, lingüísticos e etnográficos de forma a ter acesso a uma cultura estranha, no nosso caso, a dos indígenas brasileiros, cuja inferioridade em relação à civilização branca poderia ser comprovada através de argumento científico explicitado aqui.

O reconhecimento das fronteiras brasileiras no Norte e Centro-Oeste se tornou uma necessidade primordial para a consolidação da soberania sobre o território. O processo civilizador dos grupos indígenas serviu para a integração do litoral ao sertão, sendo esta etapa o passo mais importante para a conquista da região.

Ao analisarmos um Relatório do Ministério da Guerra, de 1929, sobre o estudo de um Anteprojeto para a defesa da Bacia Amazônicaª, observamos o questionamento de aspectos relacionados à unidade nacional, através do progresso e desenvolvimento do sertão, em parte vindo a corroborar a nossa hipótese intervencionista da Comissão de Inspeção de Fronteira.

Segundo o relator, uma grande parcela de culpa, pela falta de desenvolvimento da região, é relacionada aos maus governos que, por incompetência, ou por falta de patriotismo (virtude que o relator considera primordial aos oficiais 
do Exército brasileiro), fazem péssimo uso das riquezas naturais. Segundo o relator, o ciclo econômico da borracha foi outro fator incidente sobre o pouco desenvolvimento destas regiões do Amazonas, visto que muitos governos ainda se mantinham iludidos com o alto valor do produto, nos tempos áureos em que as cidades mantiveram um desenvolvimento ilusório, que foi perdido com o descaso das autoridades e do povo em si, pois o lucro fácil de outros tempos foi reduzido a uma mínima lucratividade pela desvalorização do produto, com a concomitante baixa das rendas públicas e, como resultado nefasto, o cessar de obras públicas necessárias à manutenção do funcionamento de serviços de melhoramento essencial à vida da população.

O que observei na análise das fotografias é que realmente tais melhoramentos só existiam em algumas cidades mais urbanizadas, pois em outras cidades mais afastadas, principalmente naquelas próximas às fronteiras, os serviços praticamente não existiam. Cidades que mais pareciam lugarejos com poucas casas arruinadas, pouco populosas e com uma produtividade quase nula, como era o caso de Gurupá.

Com relação aos povos da região, os integrantes da expedição de 1929 formulam um conceito próprio sobre a falta de civilização:

[...] o enfraquecimento physico e intellectual do povo, mormente dos caboclos que ainda permanecem nas trevas da ignorância, pela carência de escolas, sem ambição porque nunca sentiram vida melhor do que aquella mizeravel em que elles passam, cubertos de andrajas e famintos, ao cio, nas suas esburacadas habitações lacustres, longe geralmente de qualquer centro civilisado.

O trecho por si só já desvendaria todo nosso interesse teórico de processo civilizador, ou seja, uma visão antagônica de litoral civilizado e sertão atrasado, espaço que precisa ser resgatado pela ação civilizadora dos homens conhecedores dos saberes racionais. No texto, ainda podemos destacar a referência alusiva ao caboclo, ao questionamento racial, à forma que enfraquece o tipo brasileiro e à busca da nacionalidade, não esquecendo a falta de virtudes como patriotismo e civismo. Nesse ambiente impróprio para os grupos civilizados, habita o perigo para o Estado nacional, pois esse povo seria uma presa fácil de qualquer estrangeiro mal intencionado que apresentasse promessas de melhoramentos para a população local.

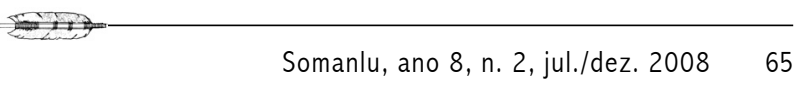


Outra crítica aparece no relatório, ao apontar para a falta de recursos e de desenvolvimento material e pessoal, que passa pelo descaso do governo central e pela exploração capitalista dos empresários que exploram o trabalho do povo.

Segundo o relator, a solução dessa crise política passaria pela ação intervencionista do Estado, não só pelas ações administrativas, como também pelas ações educacionais e pela ação sanitarista, que cuidaria das moléstias endêmicas do sertão, originadas da falta de conforto e higiene da população local.

Finalizando a discussão sobre o relatório, verificamos que o relator problematiza questões relacionadas ao melhoramento racial do povo brasileiro, feito através da imigração européia para a região amazônica. Sua conclusão bastante conservadora e determinista trata o assunto de maneira que o caboclo, se alimentado convenientemente, pode se tornar um homem sadio e útil para a sociedade. Esse resultado foi uma resposta ao condicionamento físico do europeu, que dificilmente se adaptaria ao clima quente e úmido da região.

Dentro deste contexto, passaremos à análise de algumas fotografias dos álbuns da Comissão de Inspeção de Fronteiras, que abordam os estudos etnográficos.

A primeira imagem (CPRD 036) é uma fotografia de um integrante do grupo de negros "Sarmakás", holandeses, ocupantes da região de "Tampanque", próximo de Saint Georges do Oiapoque, destacando-se marcas na região lombar. A próxima (CPRD 037) é uma foto de perfil de um negro ocupante da região no alto do rio Oiapoque. A última (CPRD 038) é a foto de um negro de pé, com sua indumentária, posando ao lado de uma pequena embarcação. Ao lançar mão de conhecimentos etnográficos, arqueológicos, lingüísticos, os expedicionários pretendiam comprovar a superioridade da civilização branca e a inferioridade de outros grupos, como índios, negros e mestiços. Por outro lado, estabeleciam as condições para realizar uma intervenção cultural nessas sociedades. 

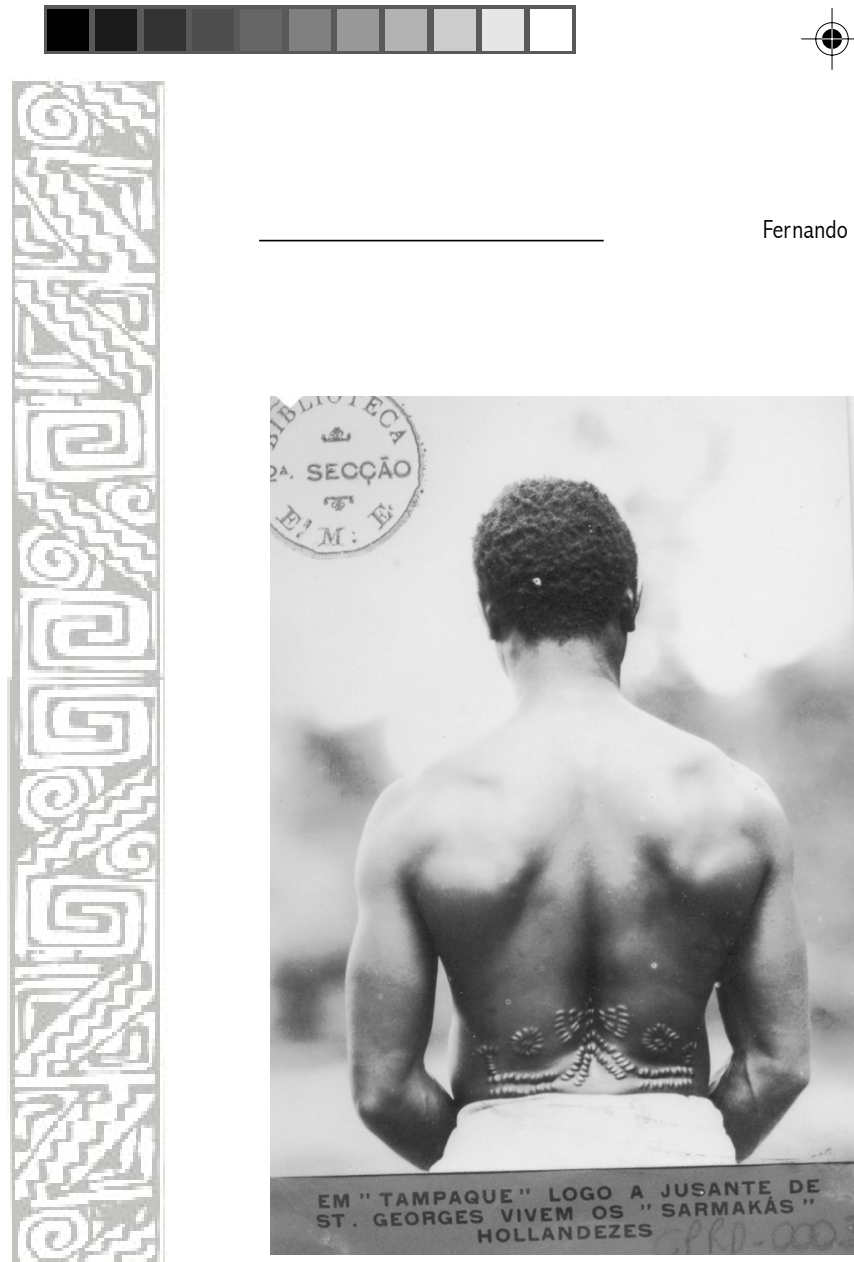

Fotografia de negro "Sarmaká"

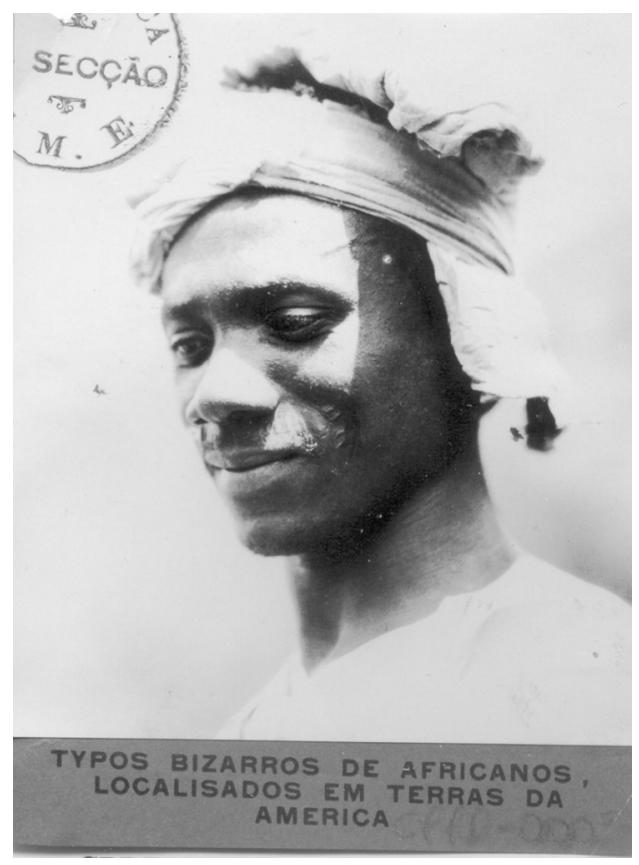

Fotografia de tipos de negros da América

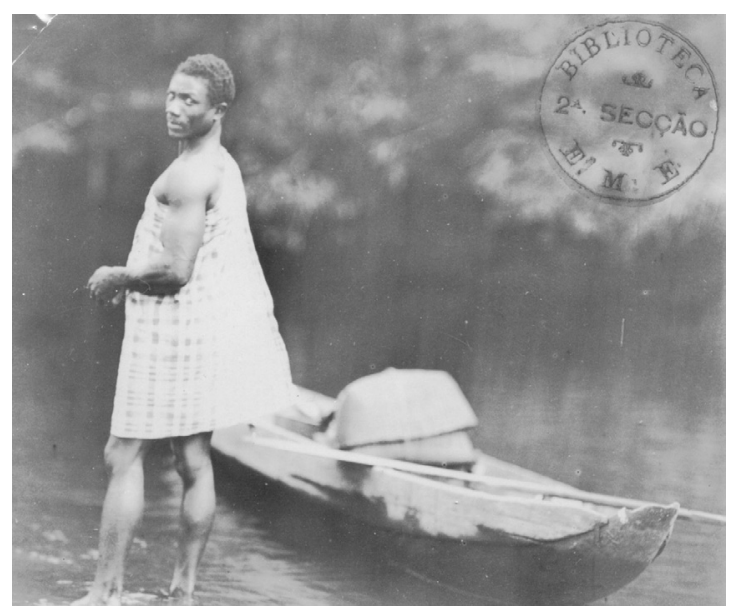

Fotografia de tipos de negros da América

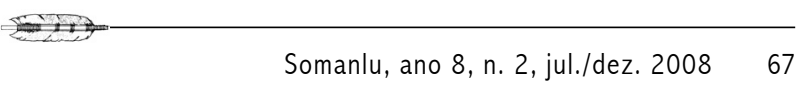


A imagem seguinte registra um casal de índios Oyampi fotografado por ocasião dos levantamentos da Inspeção de Fronteira no estado do Pará. Levantamentos etnográficos foram feitos ao longo de toda História independente brasileira, de forma que pudesse ser estabelecido o melhor processo intervencionista nesses grupos sociais.

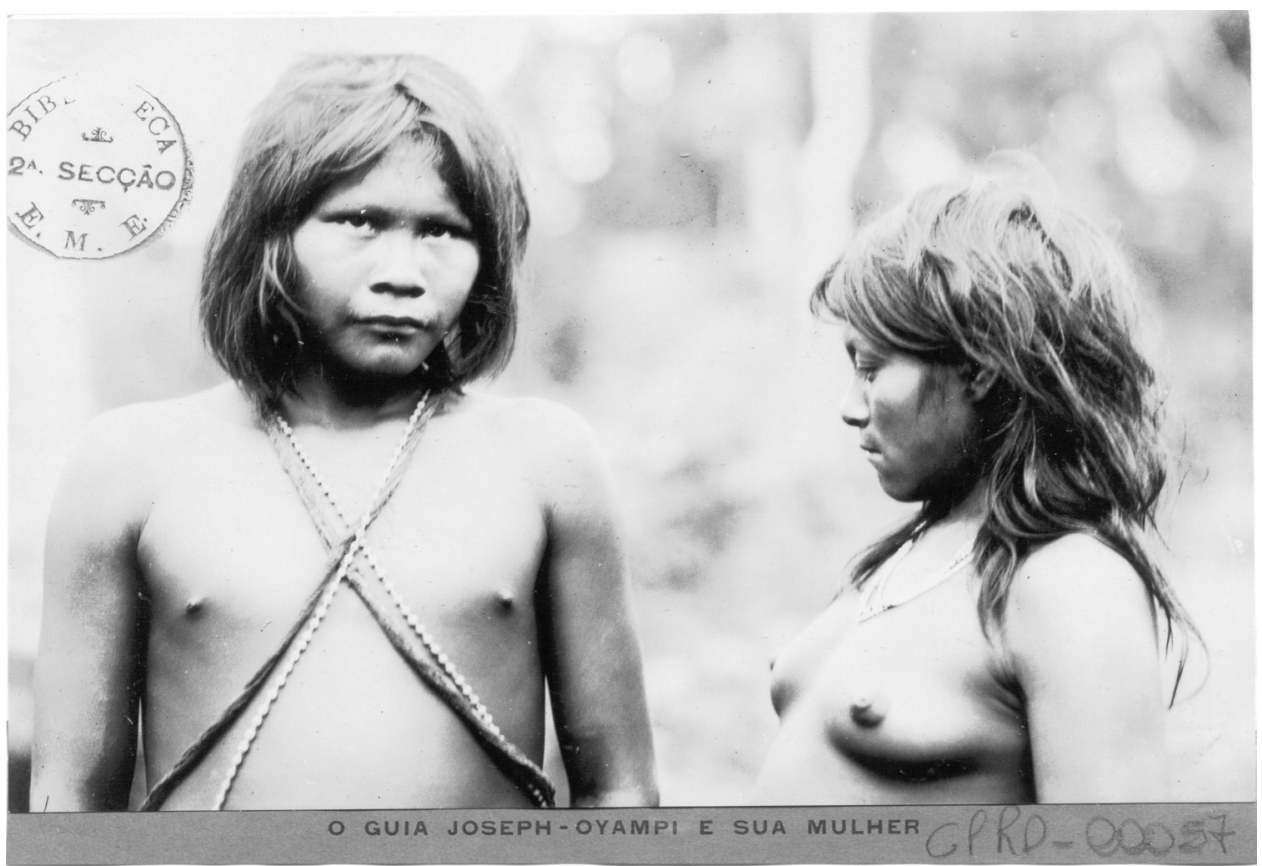

Fotografia de tipos indígenas brasileiros - Oyampi

A próxima foto (CPRD 059) é de uma mulher e de uma a criança da tribo dos Oyampi, sentadas. Costumes, modos de vida, religião, arte, tudo da cultura do outro era importante ser reconhecido, de maneira que o domínio do grupo fosse facilitado e sem o custo do uso da força. No entanto se fosse necessário, a força seria usada para dominar ou para manter os espaços conquistados. 

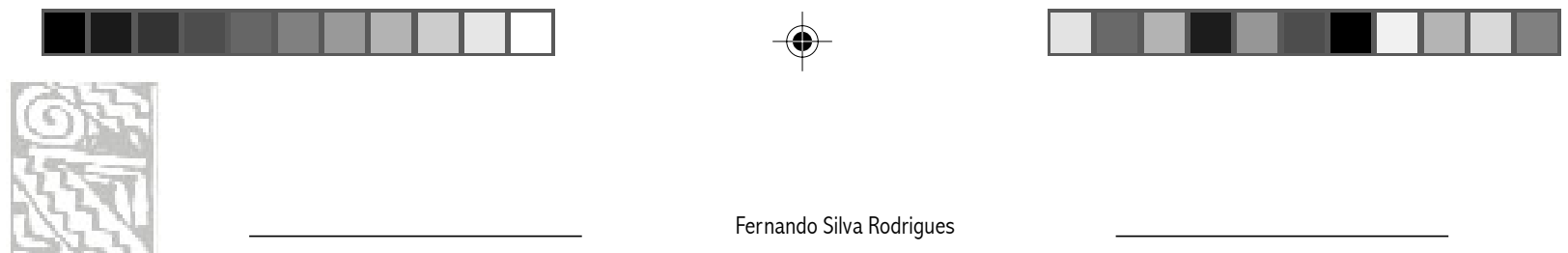

Fernando Silva Rodrigues

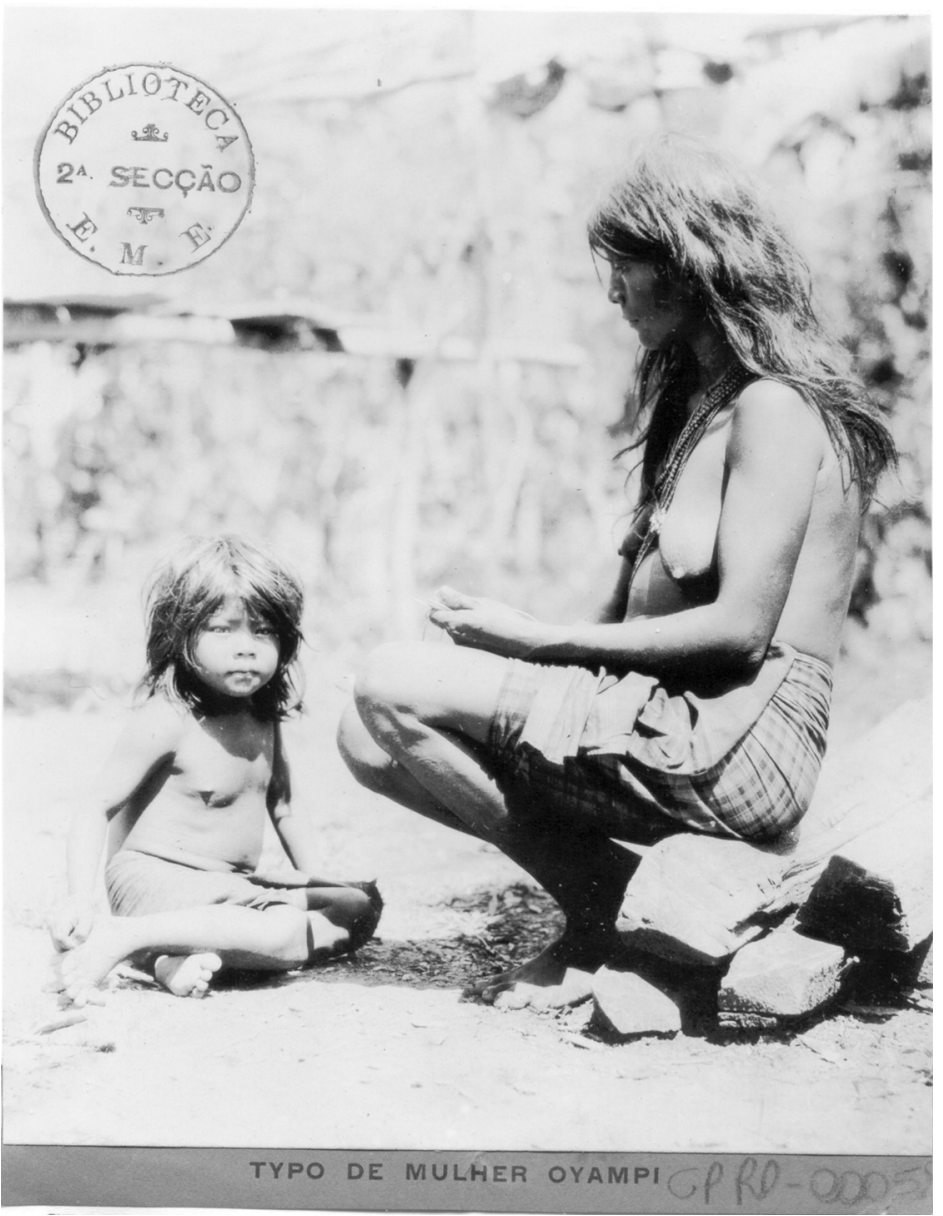

Fotografia de tipos indígenas brasileiros - Oyampi

Os registros seguintes ainda são de membros da tribo Oyampi da barra do rio Yarupi. O primeiro (CPRD 062) é de um índio adulto posando de pé com os braços cruzados. E o segundo (CPRD 063) é de uma índia grávida, de joelhos no solo, posando ao lado de jarros de barro. Não só os tipos interessavam aos expedicionários, mas também a cultura material, para estabelecer um padrão de desenvolvimento do grupo estudado. 


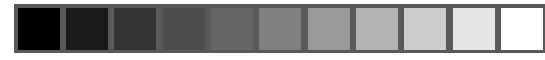

Cultura e civilização na amazônia...

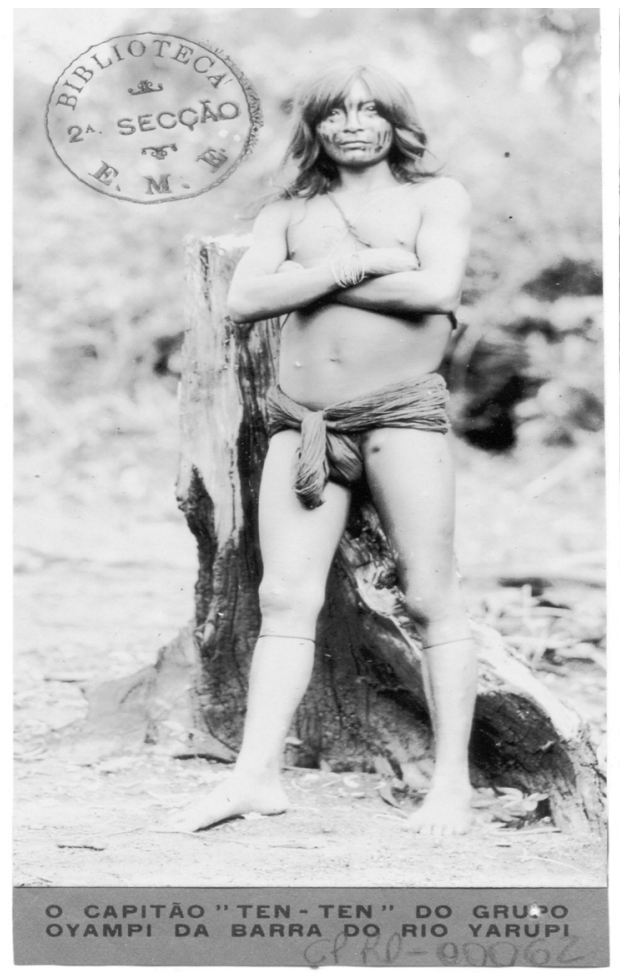

Fotografia de índio Oyampi

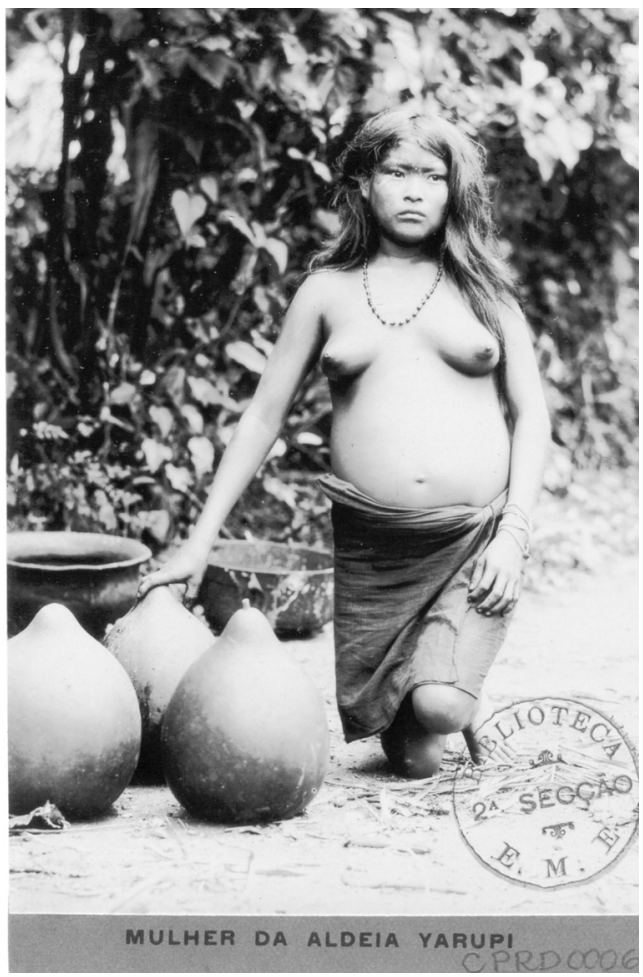

Fotografia de índia Oyampi

As fotografias seguintes são de membros da tribo Uapichana da margem inglesa do rio Tacutu, sendo a primeira de uma criança e a segunda de uma mulher com uma criança no colo. Como se percebe, os traços físicos deste grupo são bem diferentes de outros índios analisados, tendo uma pele mais clara, e o grupo parece já estar aculturado ao modo de vida civilizado, pois usar vestimentas não é comum nos grupos indígenas sem ou com pouco contato com a civilização.

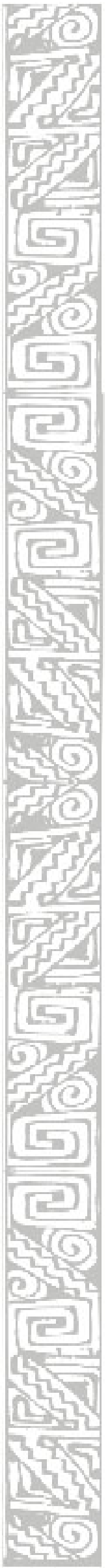



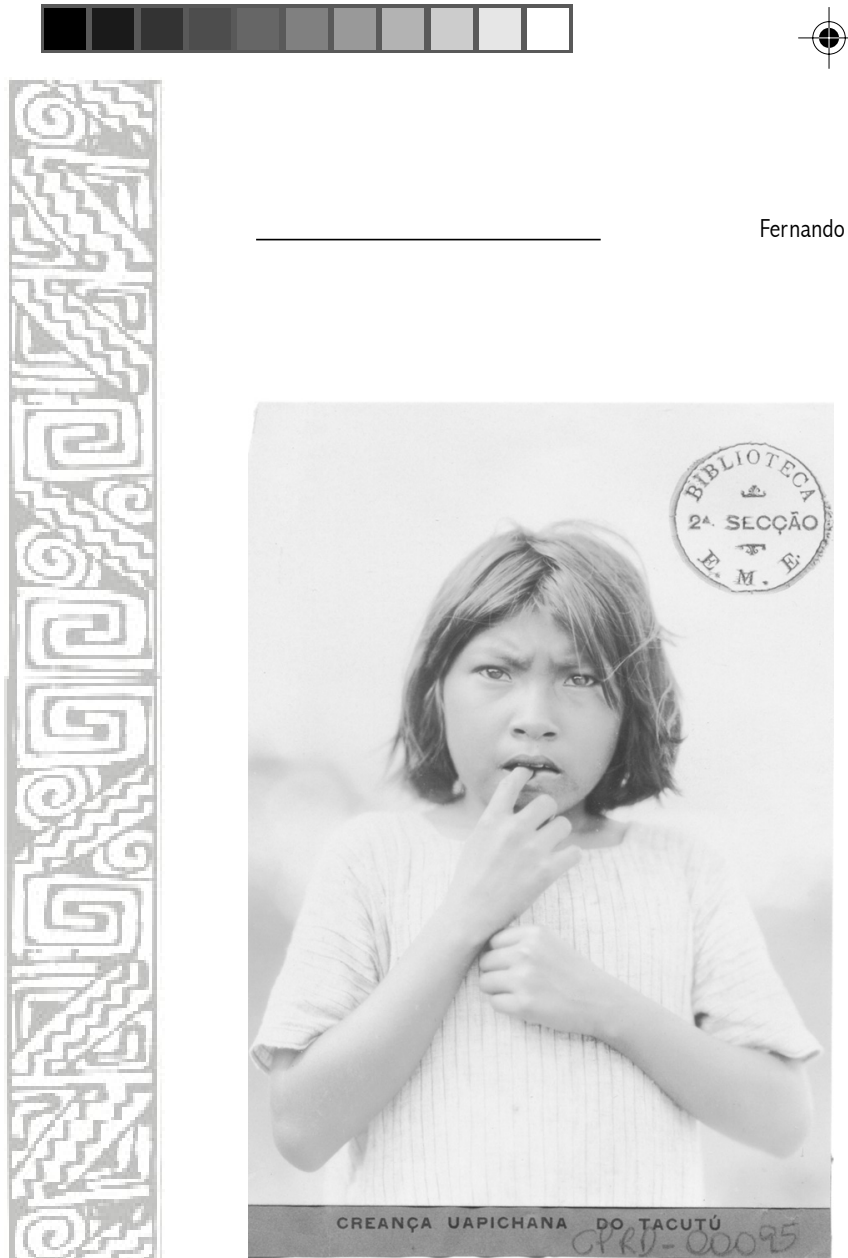

Fotografia de índio Uapichana

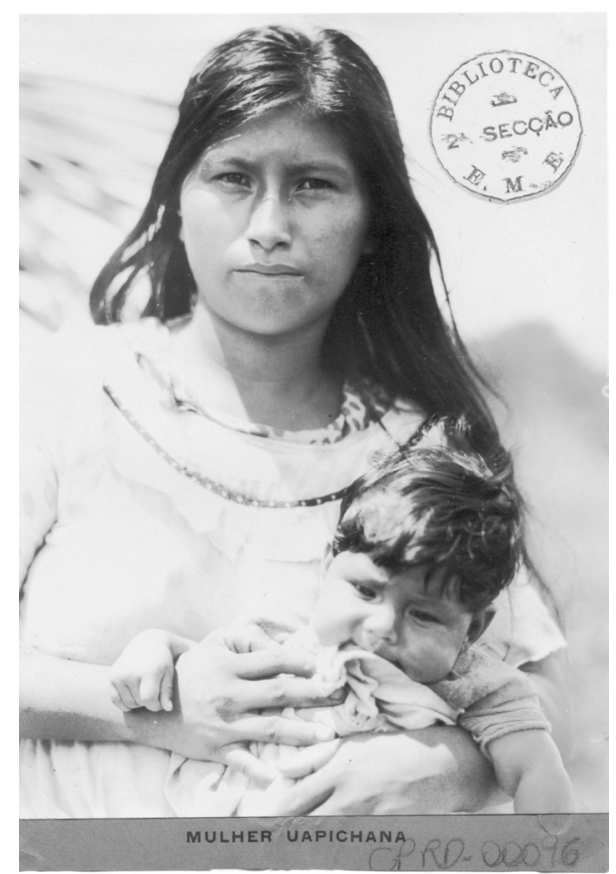

Fotografia de índia Uapichana

O próximo grupo de imagens foi feito pela turma do Capitão Polydoro Barbosa, quando da missão subindo o rio Uraricoera até atingir a cabeceira do rio Parima, na fronteira com a Venezuela. A primeira imagem é do contato dos expedicionários com os índios Maiangong, na cachoeira Tucuchiman, em frente à maloca indígena. A segunda é uma foto de frente identificando os traços da face e da cabeça de um índio Maiangong. Mais uma vez a cultura material e o tipo característico dos índios são registrados para garantir o entendimento científico e o nível de progresso deste grupo indígena analisado. 

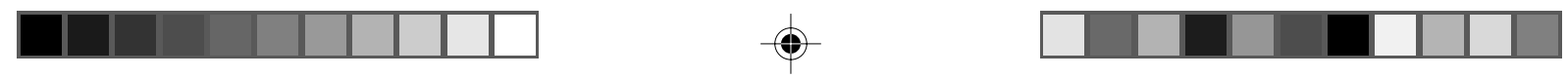

Cultura e civilização na amazônia...

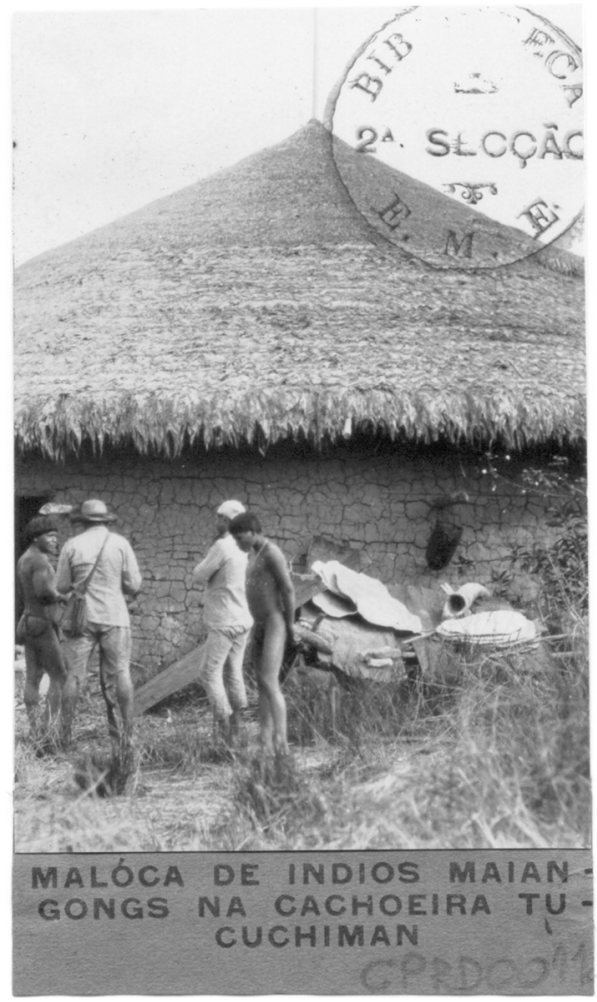

Fotografia de índios Maiangong

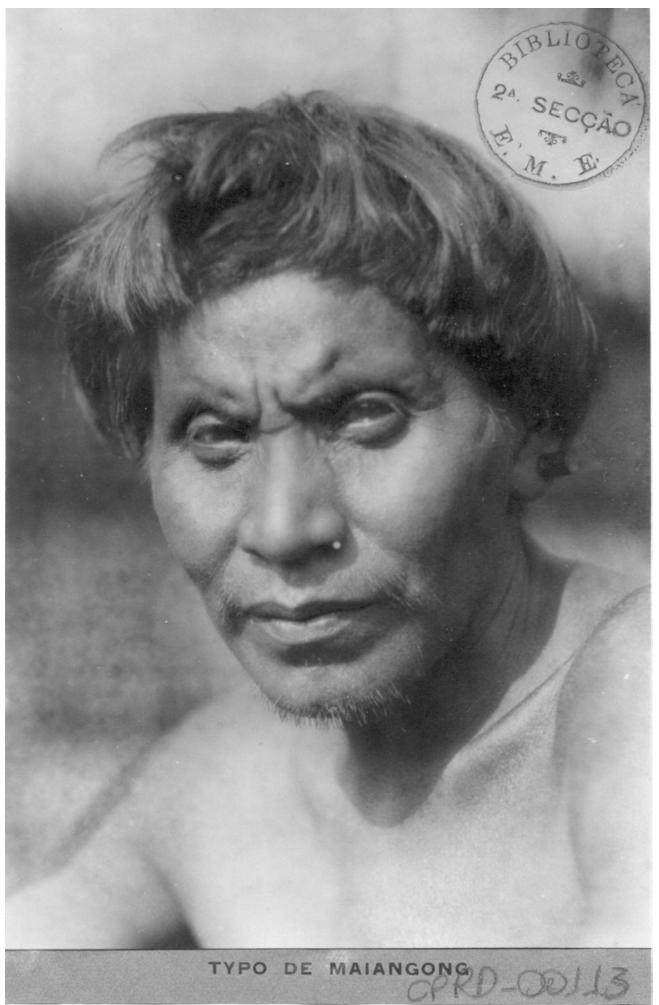

Fotografia de índio Maiangong

A fotografia seguinte registra o General Rondon junto aos integrantes da Inspeção de Fronteira no trabalho de translado de urnas funerárias indígenas na serra Maruaí para o acervo do Museu Nacional do Rio de Janeiro. No final do século XIX e início do século XX, eram comuns as expedições científicas, estrangeiras ou nacionais, que tinham como objetivo recolher produtos materiais indígenas para que fosse realizada pelas instituições científicas a análise etnográfica dos grupos, considerados povos sem cultura e sem história. 

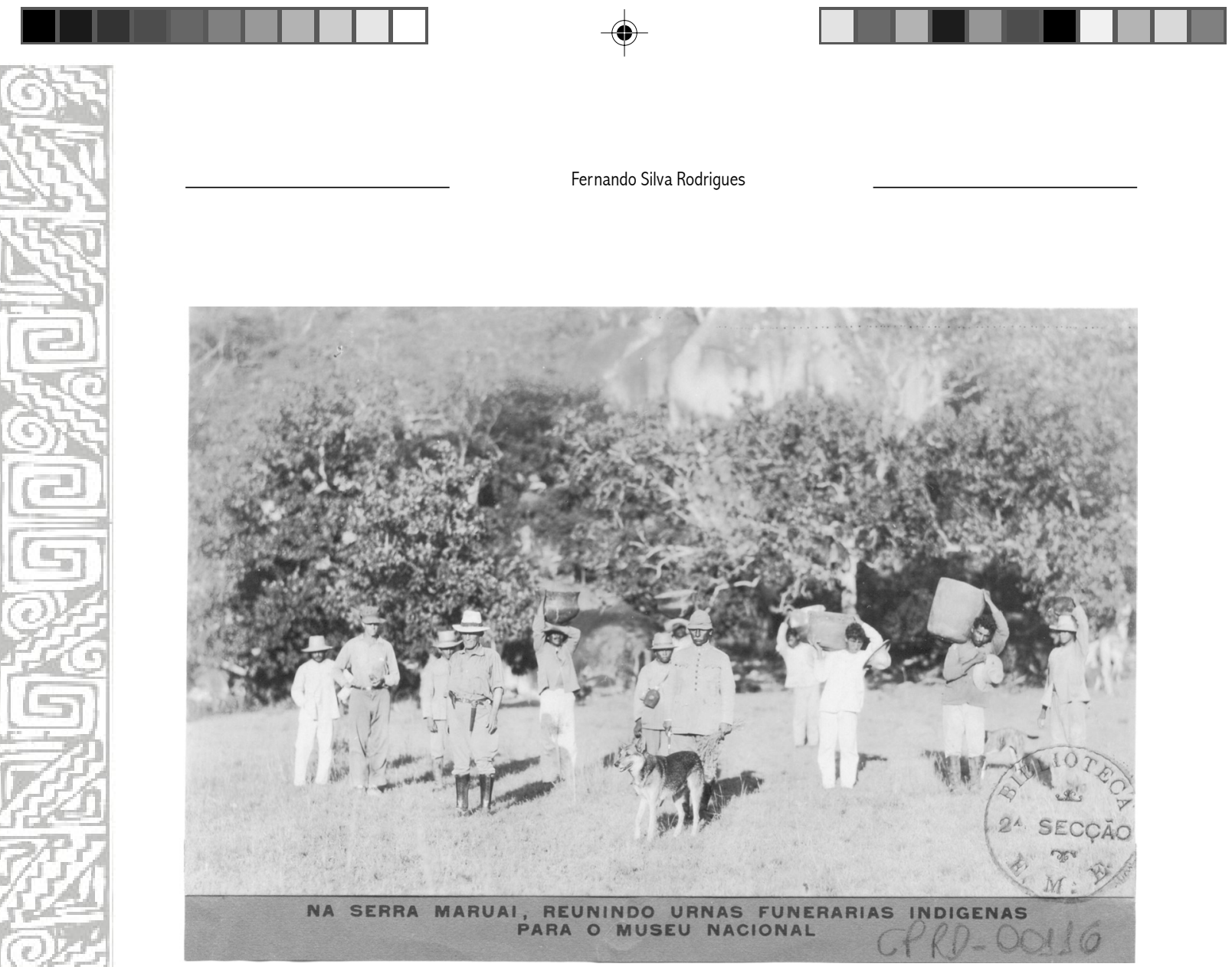

Fotografia do translado de urnas funerárias indígenas

A seguinte (CPRD 120) é uma fotografia de índios Macuchi com o Tuxaua Domingos, todos reunidos para a realização do registro. As crianças estão todas à frente do grupo, sentadas ou de joelhos; atrás estão os adultos misturados, entre si, mulheres e homens. Ao fundo da imagem, no plano esquerdo, uma grande maloca. O grupo parece já estar aculturado ao modo de vida civilizado, em virtude da vestimenta utilizada pela grande maioria deles. E a (CPRD 121) mostra os índios Macuchi durante o ritual da dança da "Parichára"; nesse momento, a cultura do grupo serve como fonte do registro, pois a festa e a cultura material são as principais fontes da memória de um grupo. Um processo civilizador fatalmente passa pela desmontagem dessas características sócioculturais. 

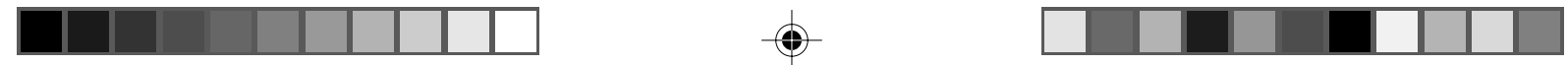

Cultura e civilização na amazônia...

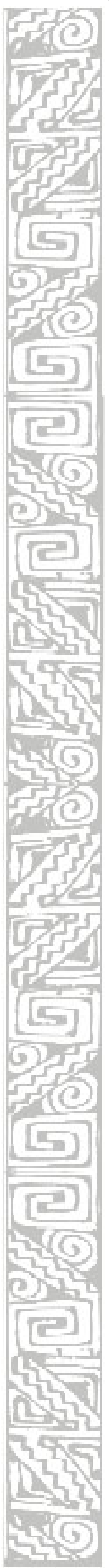



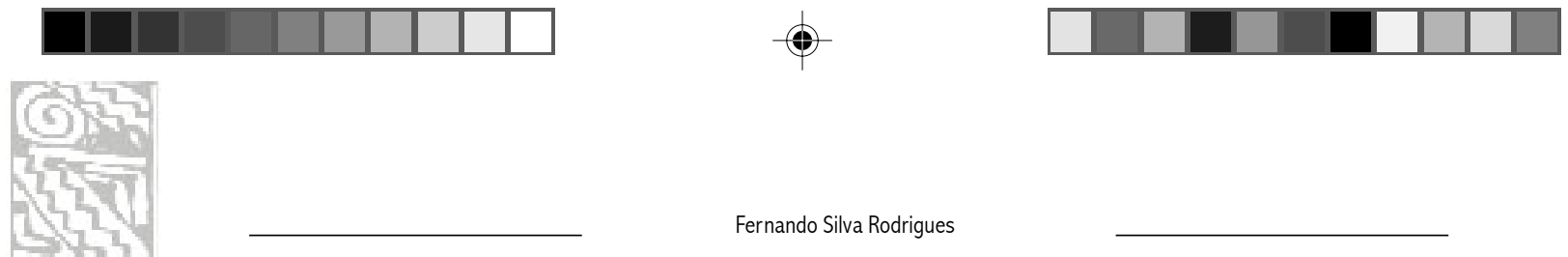

Fernando Silva Rodrigues

$\mathrm{Na}$ fotografia que se segue (CPRD 122), temos o registro de um grupo indígena do rio Surumu, formado por mulheres e crianças da Aldeia do Barros, e ao fundo, a serra Imairari. $\mathrm{Na}$ foto, aparecem dois elementos que precisavam ser conquistados pela ação civilizadora do Estado: a natureza e o homem selvagem. Em parte esse processo já tinha sido iniciado pela aculturação que este grupo sofrera.

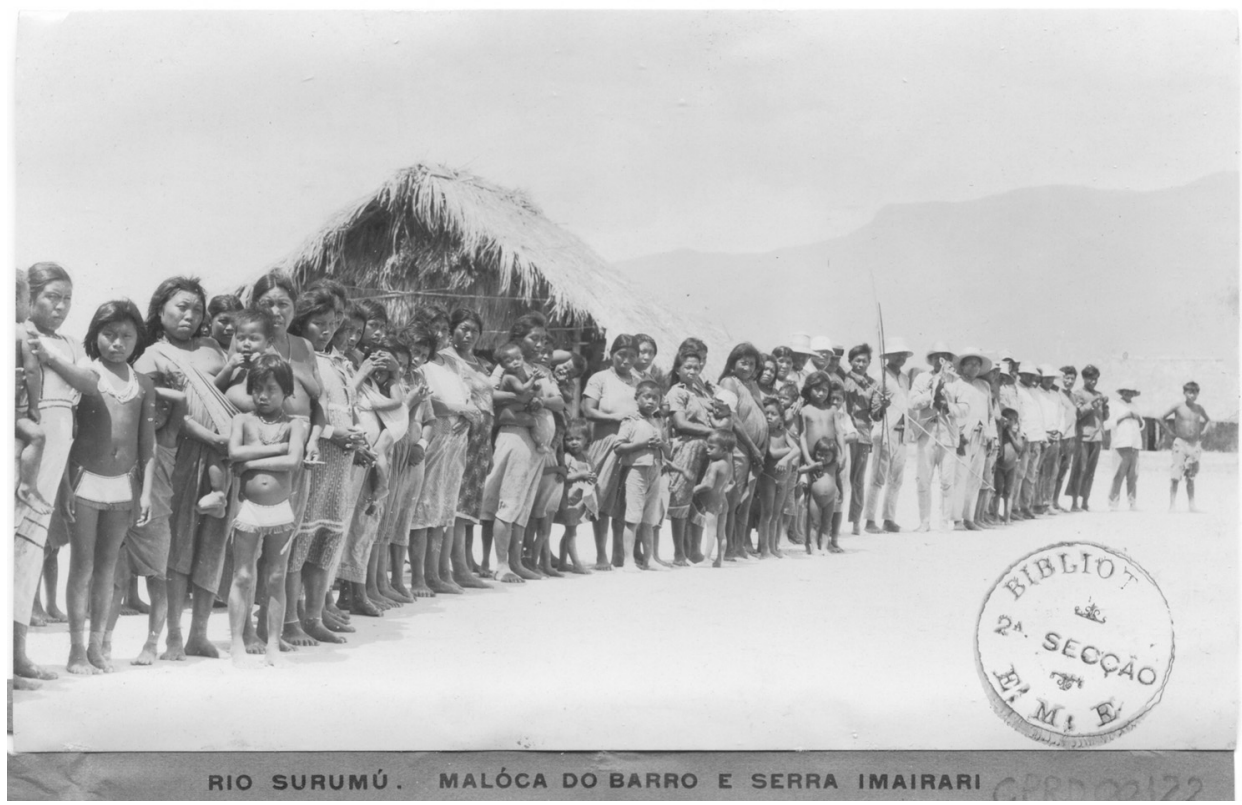

Fotografia de índios da região do rio Surumu.

Já a próxima foto é o registro de um grupo de índios de uma aldeia próxima ao rio Uailein, na Venezuela, ao fundo, verificamos a presença de uma maloca. A fotografia (CPRD 128) é a imagem de um grupo de mulheres da tribo Taurepan da Venezuela. Havia grande interesse da comunidade científica brasileira no estudo e no levantamento dos grupos indígenas, como parte importante na escolha da melhor maneira para formação da nacionalidade brasileira, a partir da inserção dos índios. 

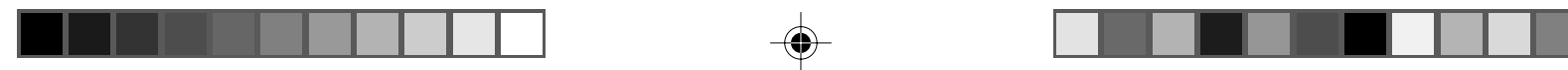

Cultura e civilização na amazônia...

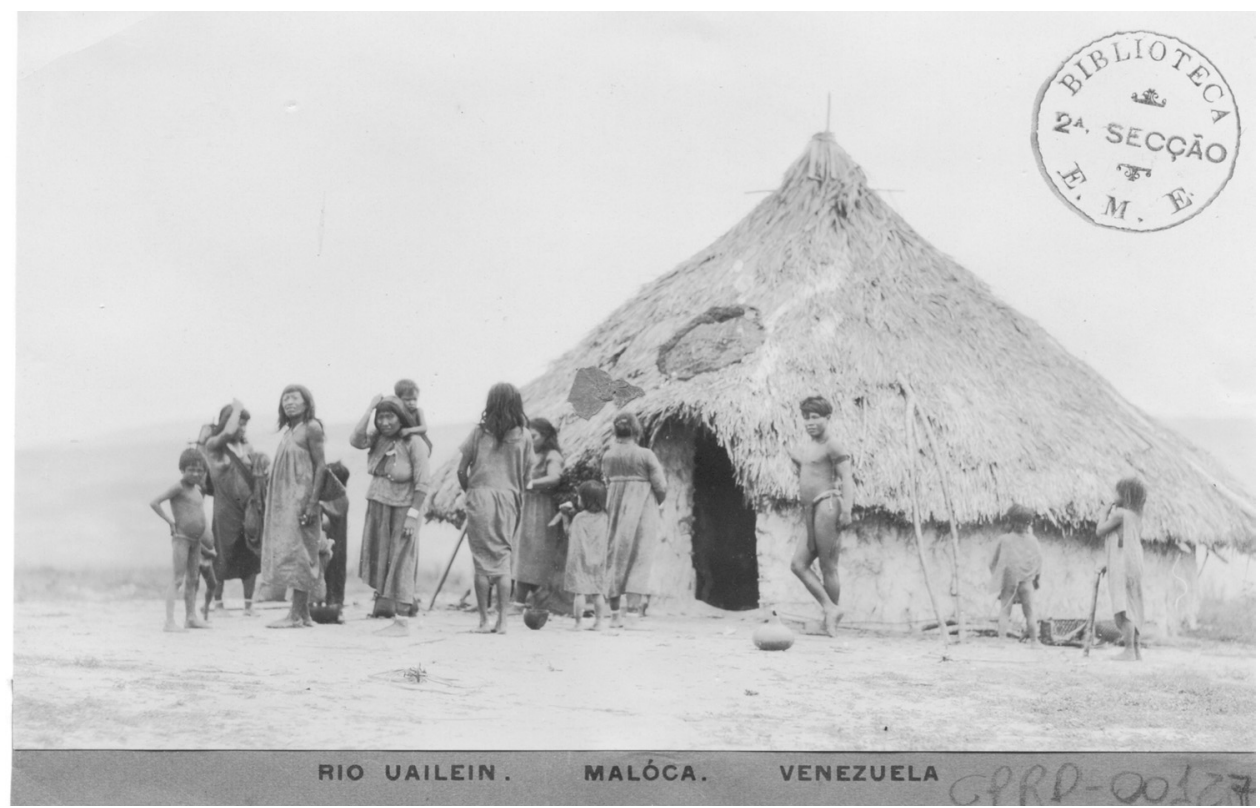

Fotografia de índios da região do rio Uailein - Venezuela

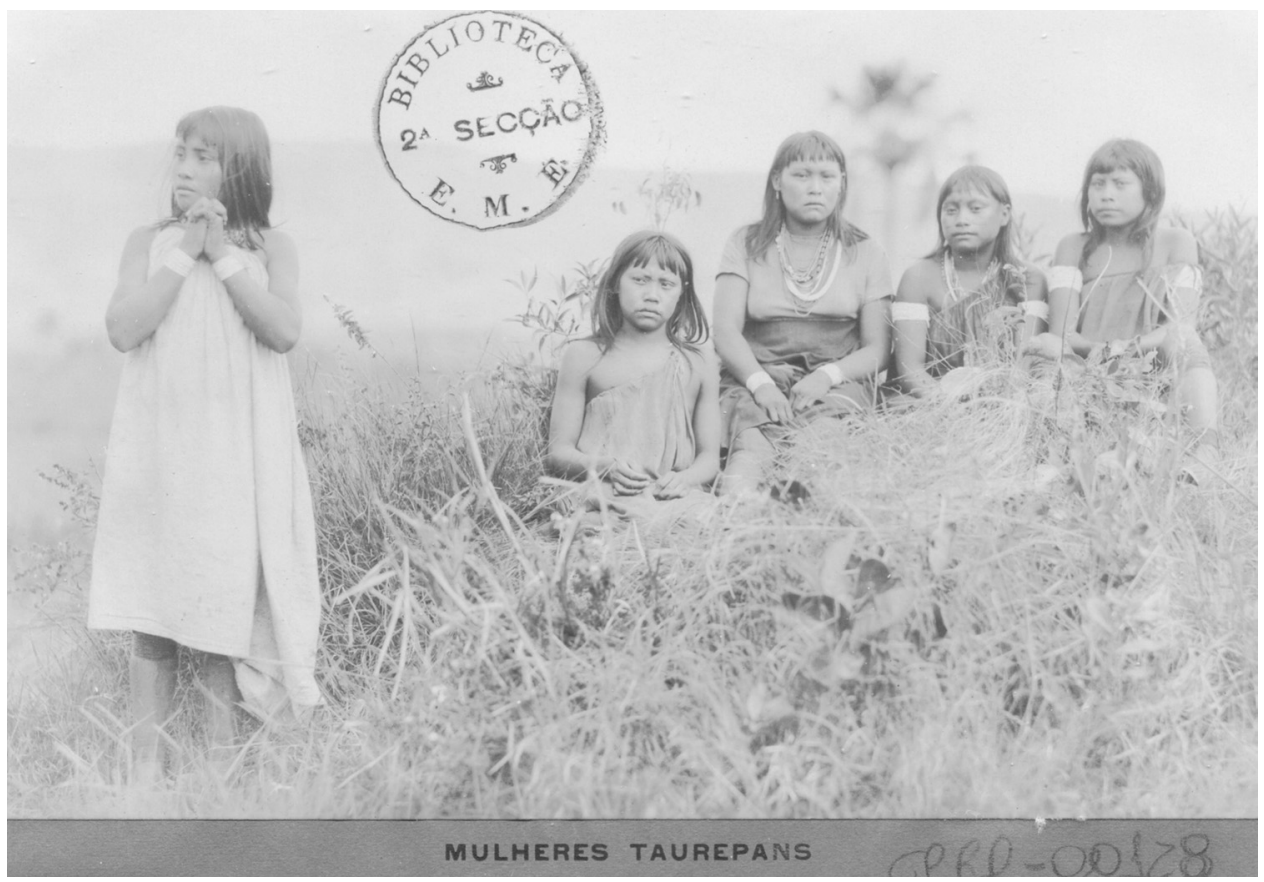

Fotografia de mulheres Taurepans 
A fotografia (CPRD 218) mostra o momento em que o General Rondon está estabelecendo os primeiros contatos com os índios Pianocotó, na aldeia Duas Canoas, na região do rio Paru, momento este em que o Estado amplia seus domínios sobre os grupos inferiores e estabelece as bases para manutenção do território nacional.

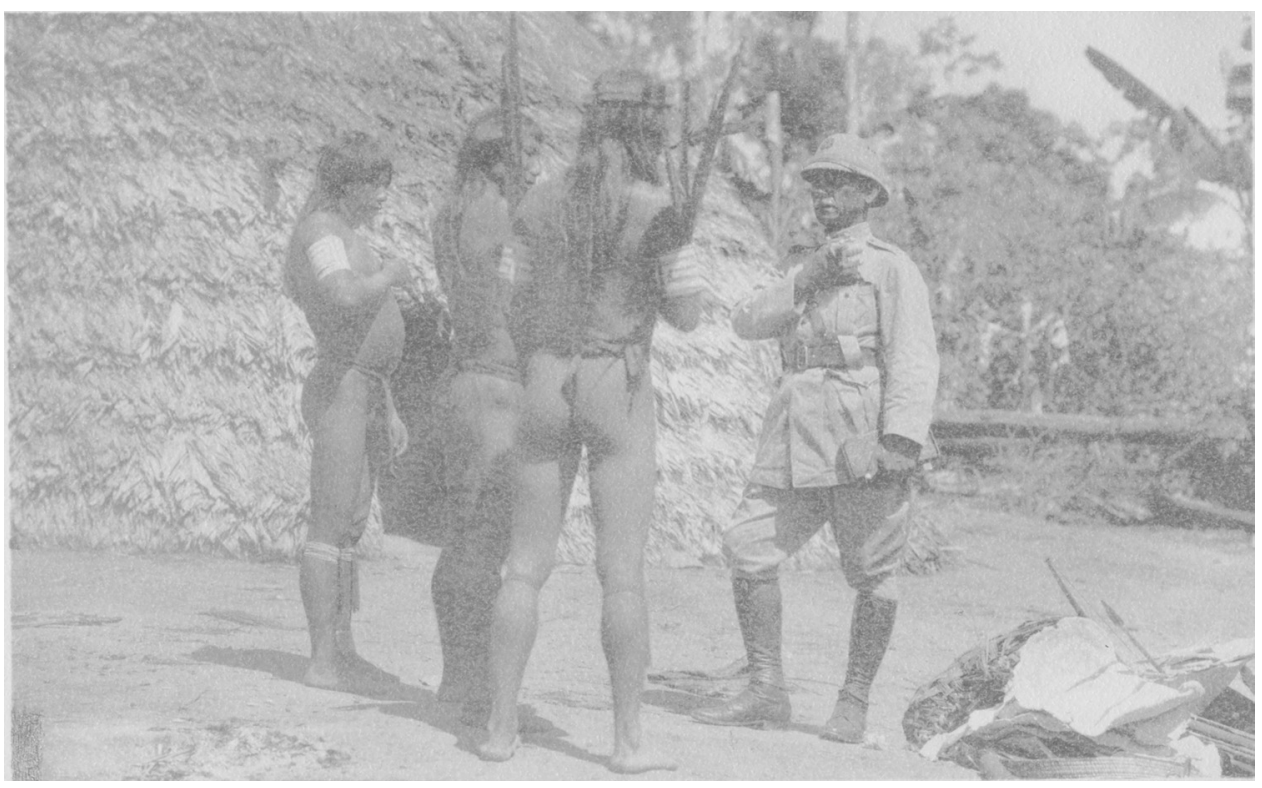

Fotografia de índios Pianocotó

Ao final dessa pesquisa, em relação às ações do General Rondon pelo sertão Norte e Centro-Oeste do Brasil, é possível que se verifiquem certas intencionalidades do Estado ao promover estas missões civilizadoras: defesa militar das nossas fronteiras na América; preservação da independência política, através da soberania sobre o território que passou a ser reconhecido nacional e internacionalmente pelas demarcações de fronteiras terrestres; reconhecimento de um território desconhecido; e o processo de integração sertão-litoral via processo civilizador dos diversos grupos indígenas, diminuindo as tensões existentes entre o litoral, dito civilizado, e o sertão, dito selvagem.

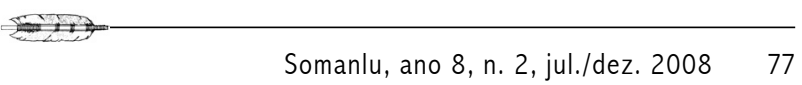




\section{Notas:}

1. O termo etnia é atribuído aos chamados povos sem escrita, marcado por preconceito racista. A etnografia é a coleta descritiva dos documentos. A etnologia é a síntese comparativa, que coloca em prática conceitos herdados da História, como o estudo de grupos humanos, tendo como objeto específico o estudo das relações de parentesco que asseguram sua coesão interna e que são regras não escritas entre pessoas que não possuem arquivos nem passado.

2. Arquivo Histórico do Exército. Acervo do Ministério da Guerra, Relatório sobre o Anteprojeto para a defesa da Bacia Amazônica, de 1929.

\section{Referências}

ALMEIDA, Rita Heloísa. O diretório dos indios, um projeto de "civilização" no Brasil do século XVIII. Brasília: UnB, 1997.

AMADO, Janaina. Região, sertão, nação. Revista de Estudos Históricos. Rio de Janeiro: v. 8, n. 15, 1995.

ELIAS, Norbert. O processo Civilizador: uma história dos costumes. Rio de Janeiro: Jorge Zahar, 1996

FERREIRA NETO, Edgard. História e Etnia. In: CARDOSO, Ciro Flamarion; VAINFAS, Ronaldo. (Orgs.). Domínios da história: ensaios e metodologia / Rio de Janeiro: Campus, 1997.

GUIMARÃES, Manoel Luís Salgado. Nação e Civilização nos Trópicos: o Instituto Histórico e Geográfico Brasileiro e o projeto de uma história nacional. Revista de Estudos Históricos. Rio de Janeiro: v. 1, n. 1, 1988.

MAGALHÃES, Coronel Amílcar A. Botelho de. Rondon, uma relíquia da pátria. Rio de Janeiro: Imprensa Nacional, 1946.

RODRIGUES, Fernando da Silva. Um olhar diferente sobre Rondon: imagens do processo civilizador do sertão centro-oeste e norte brasileiro na primeira república. Dissertação de (Mestrado) - Vassouras: USS, 2005.

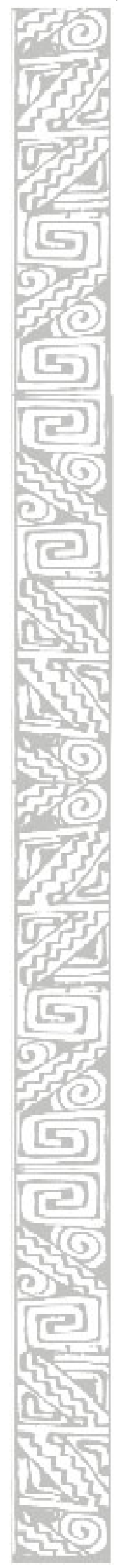

